Original Research Paper

\title{
Modeling Deformation of Spur Gear
}

\section{Vyacheslav Lyashenko ${ }^{1}$, Diana Rudenko ${ }^{2}$}

${ }^{1}$ Department of Media Systems and Technology, Kharkiv National University of Radio Electronics. Ukraine.

${ }^{2}$ Department of Informatics, Kharkiv National University of Radio Electronics. Ukraine.

Article History

Received:

27.08.2021

Revised:

14.09.2021

Accepted:

19.09.2021

*Corresponding Author:

Vyacheslav Lyashenko

Email:

lyashenko.vyacheslav@gmail.com

This is an open access article, licensed under: $\mathrm{CC}-\mathrm{BY}-\mathrm{SA}$
Abstract: In The work considers 11 types of gears, features of their design and application. Analysis of gears designs is carried out, since shape of teeth directly affects process of teeth gearing, and this, in turn, affects load, which causes deformation of elements. 3D model of spur gear was created in ANSYS system. The work was limited by analyzing problem from point of view of gear wheels' deformation, which were made of $40 \mathrm{~L}$ carbon steel and carbon composite material. As a result, finite element modeling and analysis of gears using ANSYS system was carried out.

Keywords: Cogwheel, Deformation, Modeling, Transmission, Wheel. 


\section{Introduction}

There are quite a number of different mechanisms designed to transmit force and rotation. Gear transmission has become quite widespread.

Gear wheels (GW) are the main element of gear transmission. Gear drives and mechanisms are quite common in many devices and in almost all machines, including heaviest and most powerful for transmission of power up to 65 thousand $\mathrm{kW}$. Gear drives (GD) in comparison with other mechanical transmissions have significant advantages, namely [1]:

- Small dimensions; high efficiency $(0.95-0.98)$

- Great reliability in work

- Constancy of gear ratio due to absence of slippage

- Possibility of using in a wide range of moments, speeds and gear ratios.

Machine parts are manufactured using a wide variety of metals, in most cases carbon steel. Stateof-art advanced carbon composite materials have opened up a new level of quiet, high strength, lubrication-free and precise gears. The speed of mechanism rotation depends on accuracy of gears, as well as some of its other parameters.

In manufacturing process of gears, focus is on quality, accuracy of parts, durability and compliance with specified technical standards.

Of great importance for reducing degree of deformation of gear wheels is place of their installation and own material of GW [2]. The growing demand for power transmission in cars, vehicles, elevators and generators has created an increased demand for more accurate analysis of transmission characteristics.

Although GD device is quite simple, which ultimately ensures a long service life, modeling this part will open up new possibilities, which means that topic of work is relevant.

\section{Materials and Methods}

\subsection{Related Work}

A review of literary sources showed that achievements in design and manufacture of gears are reflected by authors in many works [3] - [9]. Along with design and principle of operation, choice of material and parts characteristics modeling such as $\mathrm{GW}$ was and remains an important direction.

In work [3], a retrospective review of studies on development of gears production with wheels made of polymer materials was carried out, consisting of 164 references to works. The authors consider features of injection molding technology of gears from thermoplastics, influence of casting technological parameters on GW castings quality, software for computer modeling of technological process and optimization of composite polymer materials composition, specifics of designing technological equipment and methods for calculating geometry of working surfaces of gears castings.

The information on modern methods of computer-aided design of gear drives and forming parts of technological equipment is systematized.

The work [4] is devoted to solution of designing gear wheels by integrating production information into software, while article [5] provides information and recommendations for gear design, including sizing and lubrication.

Article [6] considers solution to issue of optimizing gear transmission. The main emphasis of authors is aimed at minimizing center-to-center distance of a cylindrical gear transmission in order to obtain appropriate optimal design parameters. In [6] along with constraints on bending strength, contact strength, interference and contact ratio, scoring has been added as design constraint in design problem.

Work [7] is also devoted to optimization only parameters of tooth surface grinding process. The authors consider instantaneous high temperature that occurs in grinding zone, which always causes burns to tooth surface due to improper selection of processing parameters. The paper proposes a mathematical model for release and thermal conductivity in process of grinding gears.

Dynamic modeling of gear using multi-body dynamics is presented in [8]. As a result, simulation model of entire crank mechanism was created.

In [9], using the ANSYS system, it is estimated as load on spur gear under various conditions and during its reconstruction. The authors use static structural and dynamic modeling.

There are also many works that discuss various methods and approaches to modeling in engineering using computers [10] - [13]. 


\subsection{Gear Design Overview}

The classical gearing scheme has been used for a long time [1].

The purpose and designs of gears are varied.

Let's start with an overview of GD types:

- External spur gearing, as shown in Figure 1. It used at medium speeds, but has a tendency to noise at high speeds.

- External gearing helical, as shown in Figure 2. It used with parallel shafts at high speeds so it is noiseless and can transfer higher loads.

- Internal gear spur, as shown in Figure 3. It used for a reducer. Which must meet requirements of compactness, and can also provide better protection against dirt due to internal teeth.

- Rack, as shown in Figure 4. It used to create linear motion.

- External chevron gearing, they can be conditionally compared with paired helical gears. It show in Figure 5 and used when it is necessary to avoid axial forces on shafts and bearings of bearings, which inevitably appear in conventional helical gears;

- Conical spur, as shown in Figure 6. It used at low peripheral speeds;

- Conical helica, as shown in Figure 7. It used when it is necessary to create axial forces in axial direction.

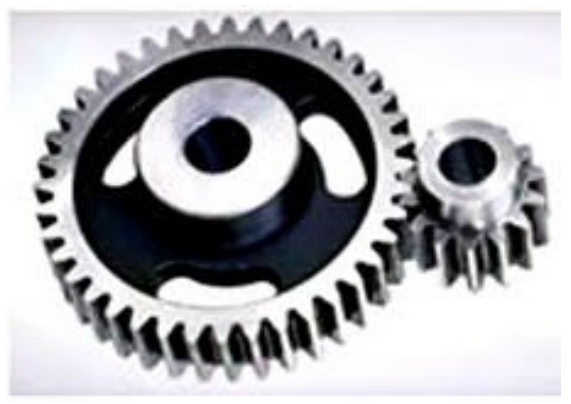

Figure 1. Type of Gears: External Spur Gearing

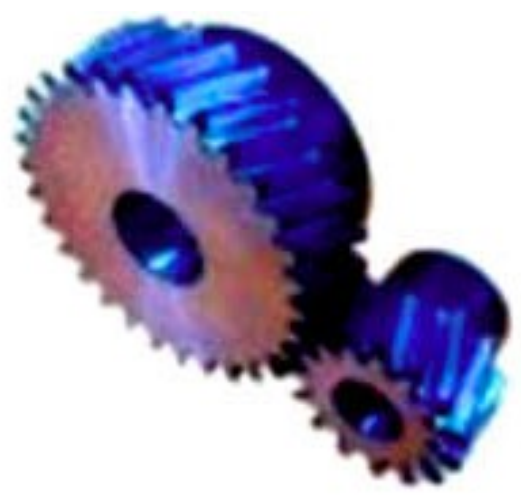

Figure 2. Type of Gears: External Gearing Helical 


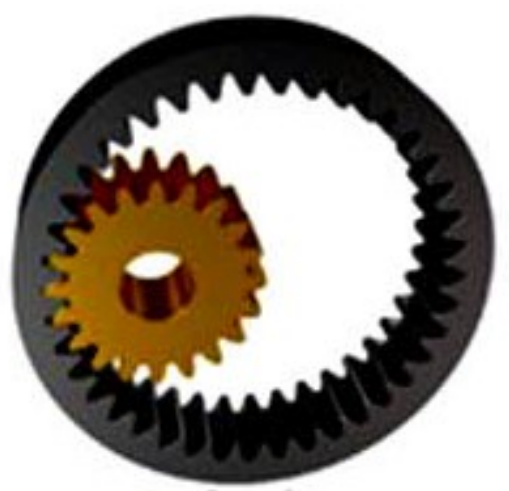

Figure 3. Type of Gears: Internal Gear Spur

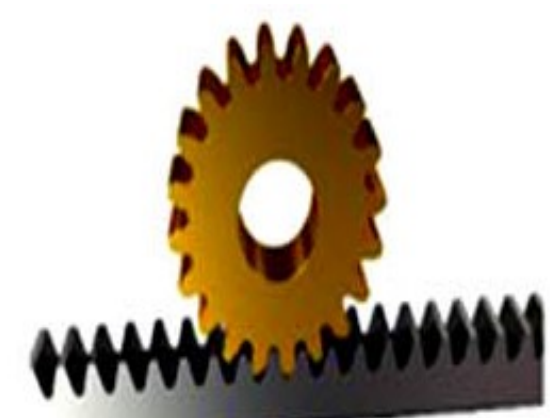

Figure 4. Type of Gears: Rack

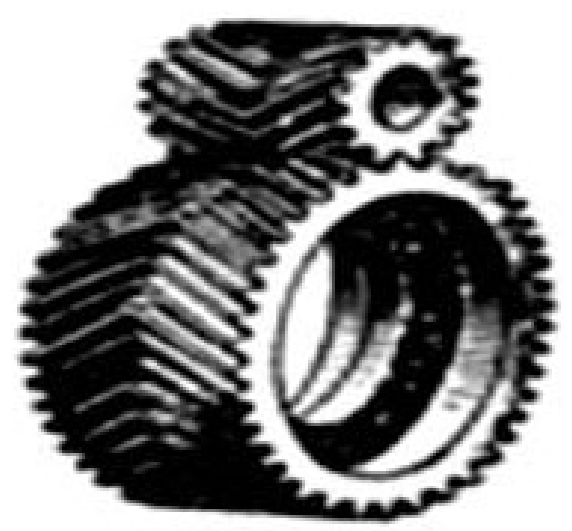

Figure 5. Type of Gears: External Chevron Gearing 


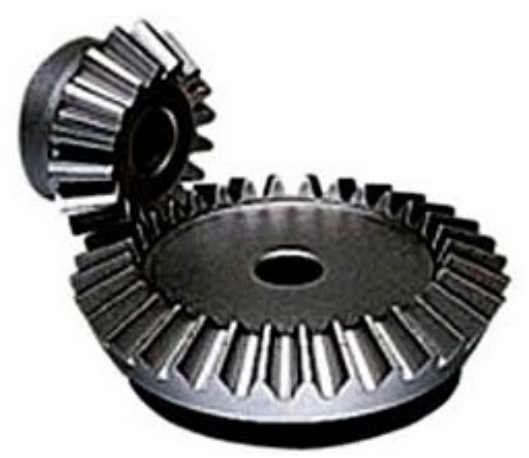

Figure 6. Type of Gears: Conical Spur

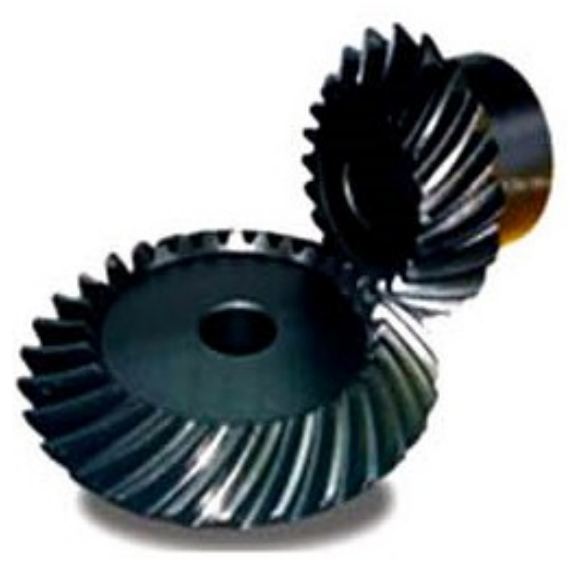

Figure 7. Type of Gears: Conical Helica

Due to higher contact ratio of teeth, they outperform straight bevel gears in efficiency, strength, vibration and noise:

- Conical circular, as shown in Figure 8. Hypoid (rotation axes of gear wheels intersect in space) is used when it is necessary to provide increased load capacity, smooth running, quiet operation, as well as increased demands on accuracy of installation.

- External gearing screw, as shown in Figure 9. It used when it is necessary to provide increased sliding in engagement and low load capacity, therefore they have limited application.

- Transmission with circular teeth, as shown in Figure 10. It used when it is necessary to provide a large contact area, contact stresses decrease and it becomes possible to transfer about 1.4-1.8 times large torques.

- Planetary gear, as shown in Figure 11. It can be used in mode of increasing speed and in cases where a variable gear ratio is required. 


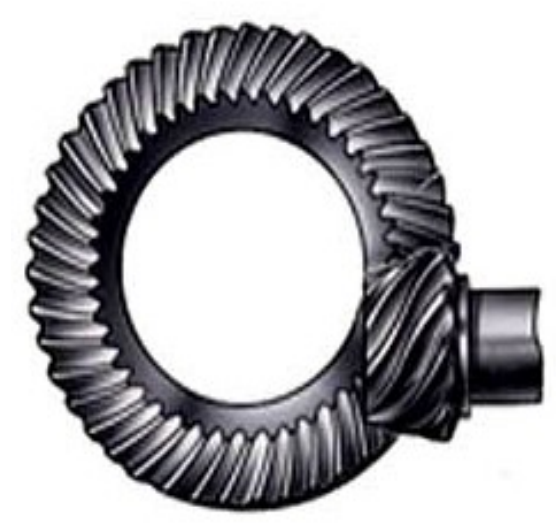

Figure 8. Type of Gears: Conical Circular

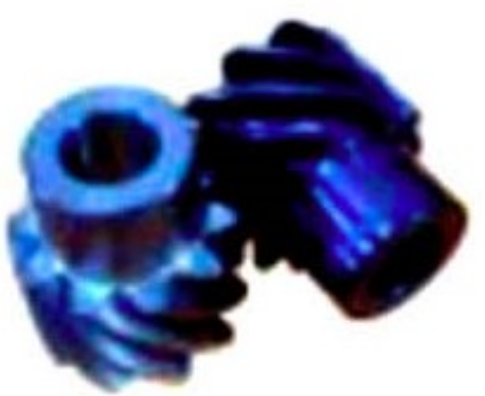

Figure 9. Type of Gears: External Gearing Screw

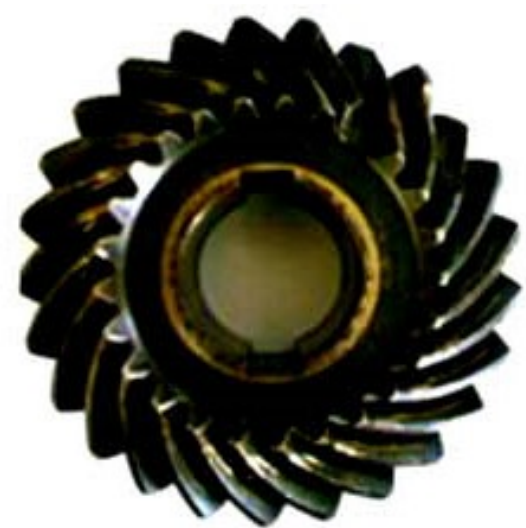

Figure 10. Type of Gears: Transmission with Circular Teeth 


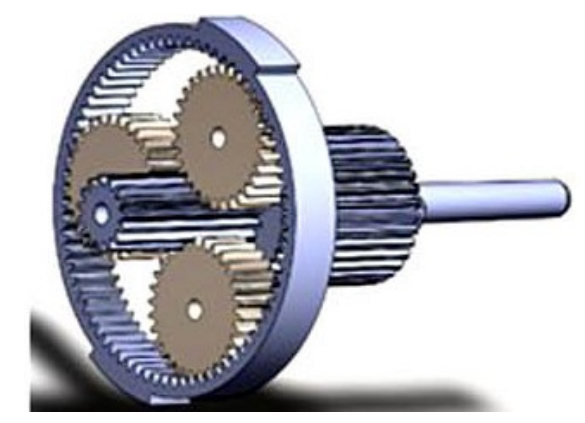

Figure 11. Type of Gears: Planetary Gear

In course of analysis, it was determined that distance between shafts of gearing is selected taking into account diameter of wheels, type of gearing, etc. While bevel gears are very widespread.

\section{Modeling Deformation of Spur Gear}

Continuing work [14], which deals with process of creating a pinion shaft, in this work, we will consider process of modeling cylindrical transmission deformation.

A pair of spurs in real life generally undergo two types of cyclic loads: contact stress and torsional stress, including bending fatigue.

However, our work focuses on type of GW material.

First, in ANSYS system, 3D model of spur gear train was created, design of which is shown in Figure 12.

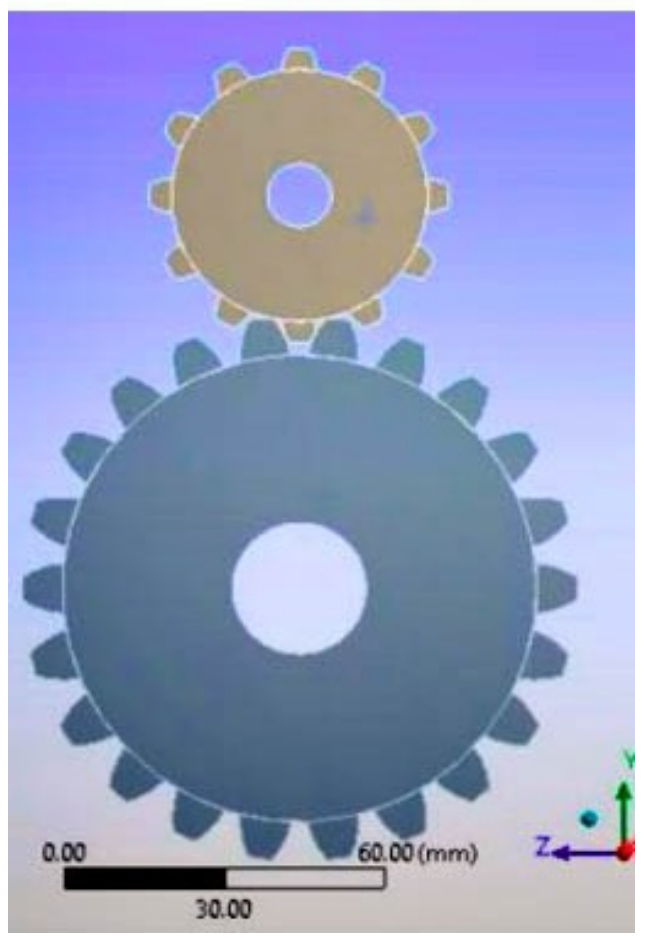

Figure 12. 3D Model of Spur Gear 
For a gear wheel made of steel material, its stress-strain state was modeled, results are shown in Figure 13 and Figure 14.

This work focuses on defining strain and stress.

The choice of gear materials must be able to withstand significant mechanical stress. The high rigidity provided by gear train helps to minimize losses in transmission of mechanical energy. However, such a design does not allow overcoming large values of dynamic load, which often leads to destruction of mechanism [15].

As an experiment, two GW materials were selected - cast steel and carbon composite material (cast iron shavings and carbon material), since it is a material for quiet, high-strength, lubrication-free and precise gears [16] [17].

In manufacture of cast gears, cast steel grades of third group are used (for particularly critical purposes), most commonly used steel grades: Gr1, J03502; 3, J04002; 4135; 4137; G41350; G41370; H41350; H41370; J13045; J13048; J13345; 35KHGSL [18].

In Figure 13 shows simulation results for cast steel while Figure 14 shows for composite material.
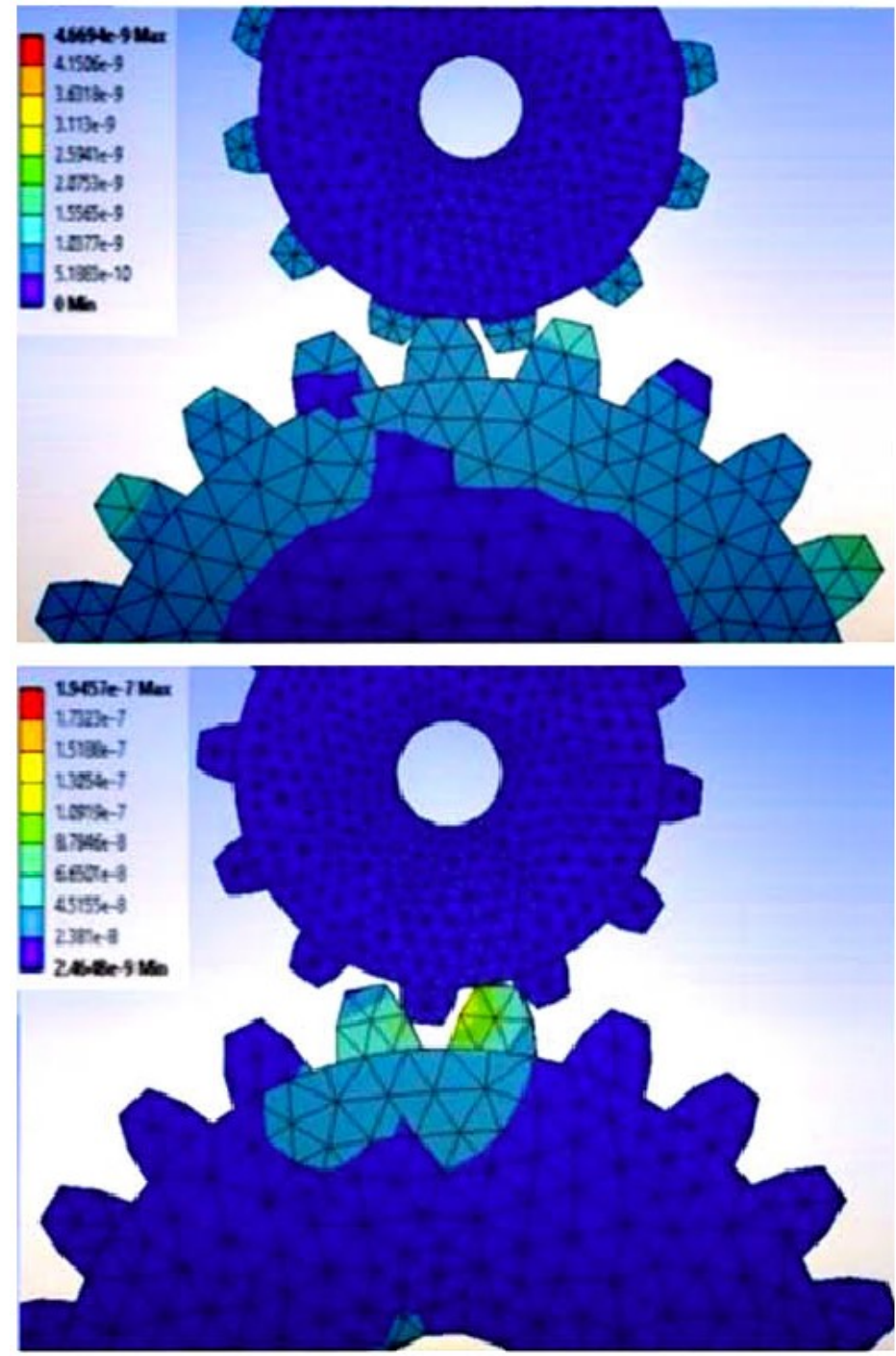

Figure 13. Deformation of Gear Drives: Cast Steel 


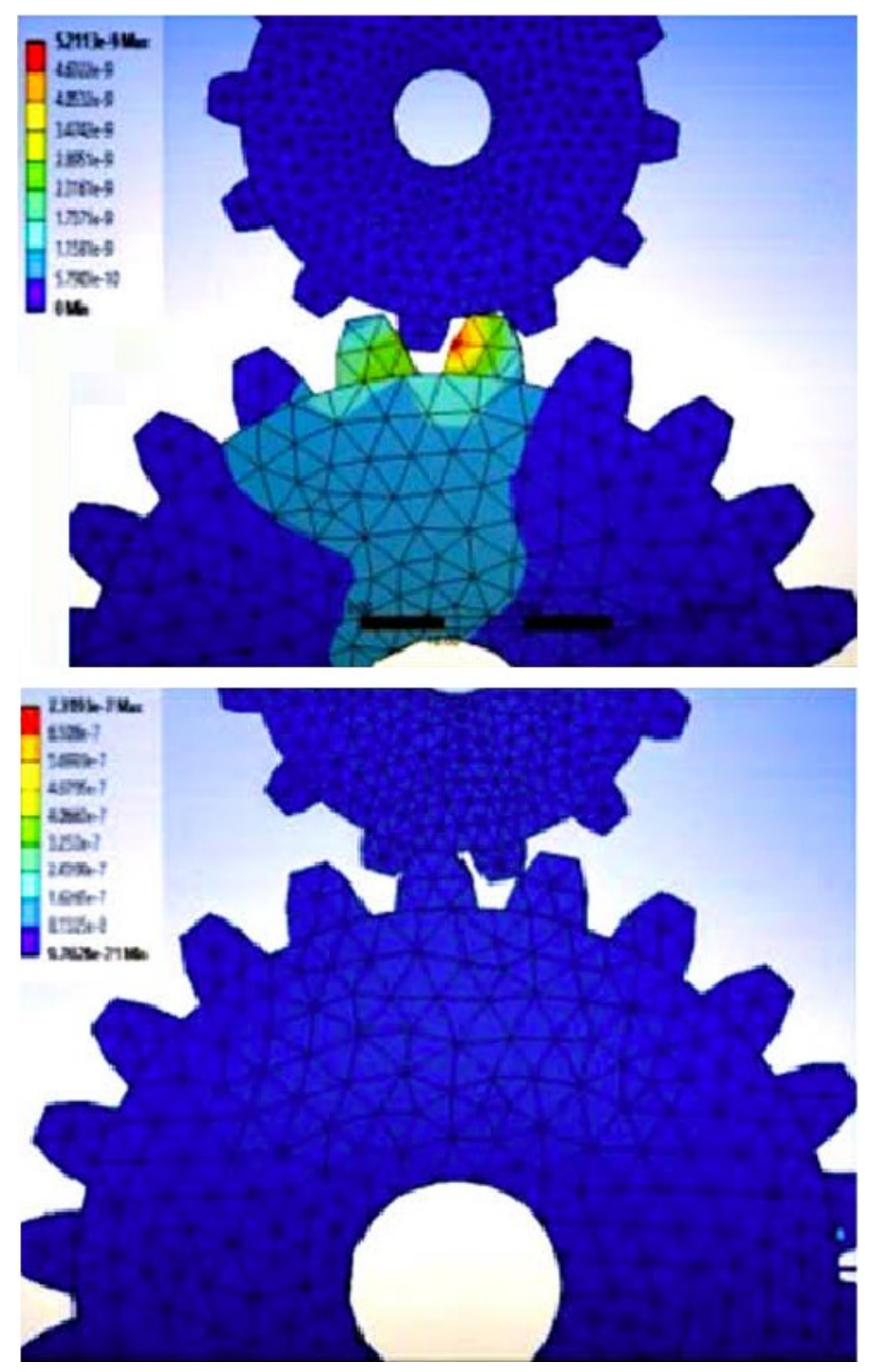

Figure 14. Deformation of Gear Drives: Composite Material

Table 1 shows simulation results in ANSYS program.

Table 1. Simulation Results

\begin{tabular}{ccccc}
\hline \multirow{2}{*}{ Indicators } & \multicolumn{2}{c}{ Carbon steel 40L } & \multicolumn{2}{c}{ Carbon composite material } \\
\cline { 2 - 5 } & $\min$ & $\max$ & $\min$ & $\max$ \\
\hline Full deformation, $\mathrm{mm}$ & 0 & 0.050307 & 0 & 0.0047467 \\
\hline $\begin{array}{c}\text { Equivalent elastic } \\
\text { deformation, } \mathrm{Pa}\end{array}$ & $9.765411 \mathrm{e} 7$ & 2.39 & $2.9338 \mathrm{e} 7$ & 0.00044866 \\
\hline Equivalent stress & 6.11679 & 179.2 & 0.11735 & 179.46 \\
\hline
\end{tabular}


Figure 15 and Figure 16 are show dependences of equivalent elastic level deformation materials from torque.

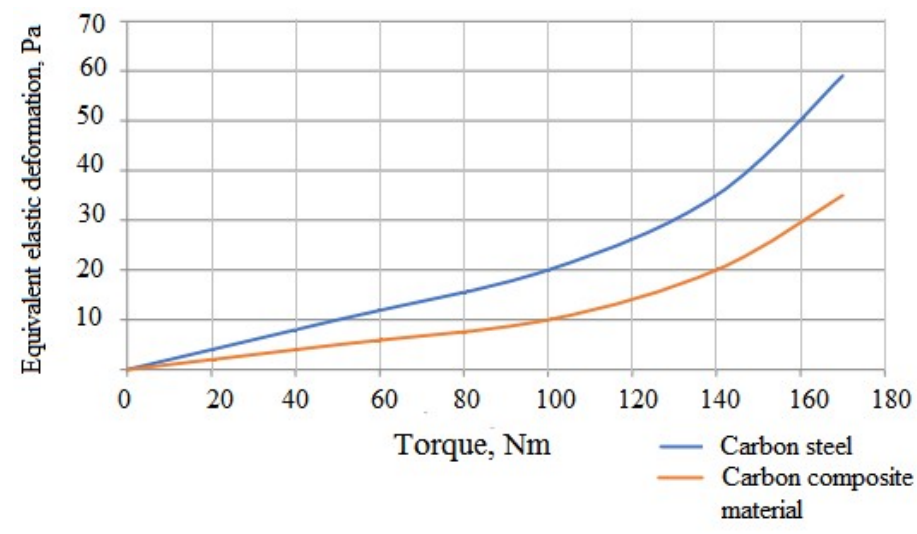

Figure 15. Comparative Characteristics of Elastic Deformations Level of For Steel

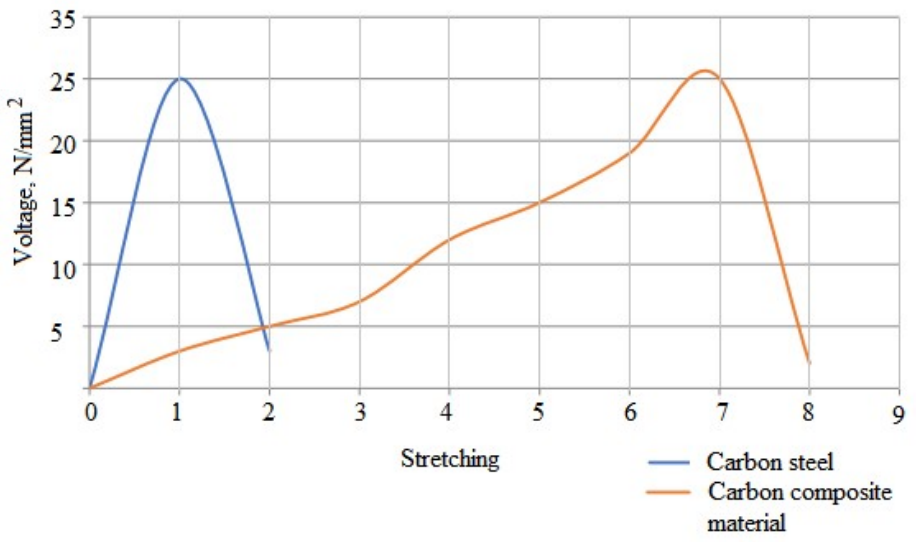

Figure 16. Comparative characteristics of elastic deformations level of for composite

Thus, it can be concluded that in process of tension in steel, critical mechanical loads are achieved faster than in a composite.

\section{Conclusions}

The work considers 11 types of gears, features of their design and application. Analysis of gears designs is carried out, since shape of teeth directly affects process of teeth gearing, and this, in turn, affects load, which causes deformation of elements. 3D model of spur gear was created in ANSYS system. The work was limited by analyzing problem from point of view of gear wheels' deformation, which were made of 40L carbon steel and carbon composite material.

As a result, finite element modeling and analysis of gears using ANSYS system was carried out. It has been determined that value of stresses for composite materials is lower compared to cast steel cylindrical gears, and in process of stretching in steel, critical mechanical loads are reached faster than in a composite, that is, the use of composite materials can be an alternative for replacing gears made of cast steel. 


\section{References}

[1] Ya. M. Radkevich, and A. G. Skhirtladze, "Metrologiya, standartizaciya i sertifikaciya", Izdatel'stvo Yurayt, 2013.

[2] S. P. Radzevich (Ed.), “Advances in Gear Design and Manufacture”, CRC Press, 2019.

[3] V. E. Starzhinskij, S. V. SHil'ko, and E. V. SHalobaev, "Tekhnologiya proizvodstva zubchatyh koles iz termoplastichnyh polimernyh materialov (obzor)", Polimernye materialy i tekhnologii, vol. 4, no 2, pp. 6-10, 2018.

[4] U. Kissling, U. Stolz, and A. Türich, "Combining gear design with manufacturing process decisions", In International Conference on Gears (Garching/Munich, Germany), pp. 1532$1544,2019$.

[5] D. Croccolo, M. De Agostinis, G. Olmi, and N. Vincenzi, "A Practical Approach to Gear Design and Lubrication: A Review", Lubricants, vol. 8, no. 9, pp. 84, 2020, 10.3390/lubricants8090084.

[6] P. Rai, and A. G. Barman, "Design optimization of spur gear using SA and RCGA", Journal of the Brazilian Society of Mechanical Sciences and Engineering, vol. 40, no. 5, pp. 1-8, 2018, 10.1007/s40430-018-1180-y.

[7] J. Su, Q. Ke, X. Deng, and X. Ren, "Numerical simulation and experimental analysis of temperature field of gear form grinding", The International Journal of Advanced Manufacturing Technology, vol. 97, no. 5, pp. 2351-2367, 2018.

[8] T. Kuivaniemi, A. Mäntylä, I. Väisänen, A. Korpela, and T. Frondelius, "Dynamic gear wheel simulations using multibody dynamics", Rakenteiden Mekaniikka, vol. 50, no. 3, pp. 287-291, $2017,10.23998 / \mathrm{rm} .64944$.

[9] A. Islam, and M. Islam, "Stress on spur gear and simulation for micro hybrid systems by Ansys workbench", Journal of Mechanical and Energy Engineering, vol. 3, no. 43-1, pp. 25-30, 2019, 10.30464/jmee.2019.3.1.25.

[10] V. Lyashenko, M. A. Ahmad, S. Sotnik, Z. Deineko, and A. Khan, "Defects of communication pipes from plastic in modern civil engineering", International Journal of Mechanical and Production Engineering Research and Development, vol. 8, no. 1, pp. 253-262, 2018.

[11] M. H. Al-Sherrawi, V. Lyashenko, E. M. Edaan, and S. Sotnik, "Corrosion as a Source of Destruction in Construction", International Journal of Civil Engineering and Technology, vol. 9, no. 5, pp. 306-314, 2018.

[12] M. H. Ahmad, V. V. Lyashenko, V. A. Lyubchenko, A. Khan, and O. A. Kobylin, "The Methodology of Image Processing in the Study of the Properties of Fiber as a Reinforcing Agent in Polymer Compositions", International Journal of Advanced Research in Computer Science, vol. 7, no. 1, pp. 15-18, 2016.

[13] A. Khan, S. Joshi, M. Ahmad, and V. Lyashenko, "Some Effect of Chemical Treatment by Ferric Nitrate Salts on the Structure and Morphology of Coir Fibre Composites", Advances in Materials Physics and Chemistry, vol. 5, pp. 39-45, 2015.

[14] V. Lyashenko, S. Sotnik, and M. A. Ahmad, "Monitoring the Process of Gear Shaft Creating", International Journal of Engineering Trends and Technology (IJETT), vol. 64, no. 3, pp. 123$125,2018$.

[15] V. V. Mozharovskij, M. V. Moskaleva, and D. S. Kuz'menkov, "Raschet izgibnyh peremeshchenij zub'ev zubchatyh koles iz kompozitov", Problemy fiziki, matematiki i tekhniki, vol. 4, no. 41, pp. 59-64, 2019.

[16] R. Khanna, and P. K. Sinha, "Structural Analysis of Spur Gear with Composite Material Under Different Loading Conditions", In Recent Advances in Mechanical Engineering (Springer, Singapore), pp. 599-604, 2021, 10.1007/978-981-15-8704-7_73.

[17] P. G. Catera, D. Mundo, A. Treviso, F. Gagliardi, and A. Visrolia, "On the design and simulation of hybrid metal-composite gears", Applied Composite Materials, vol. 26, no. 3, pp. 817-833, 2019, 10.1007/s10443-018-9753-6.

[18] S. Mahendran, K. M. Eazhil, and L. S. Kumar, "Design and analysis of composite spur gear", International Journal of Research and Scientific Innovation, vol. 1, no. 6, pp. 42-53, 2014. 